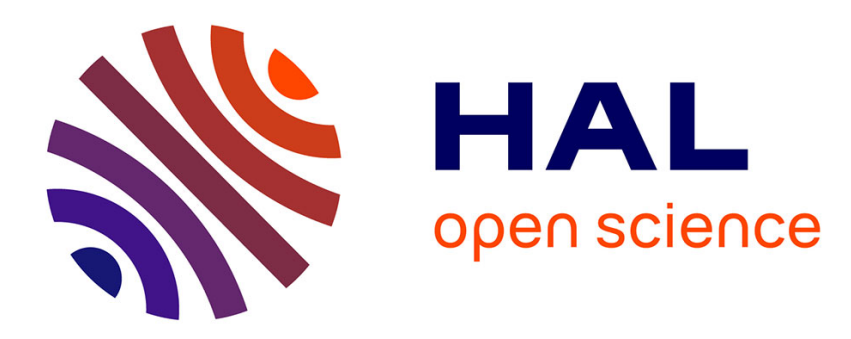

\title{
A New Parameter Characterising the Ballistic Performance of Ceramics
}

K. Hoog, H.-J. Ernst, T. Wolf

\section{To cite this version:}

K. Hoog, H.-J. Ernst, T. Wolf. A New Parameter Characterising the Ballistic Performance of Ceramics. Journal de Physique IV Proceedings, 1997, 07 (C3), pp.C3-241-C3-246. 10.1051/jp4:1997343 . jpa00255500

\section{HAL Id: jpa-00255500 https://hal.science/jpa-00255500}

Submitted on 1 Jan 1997

HAL is a multi-disciplinary open access archive for the deposit and dissemination of scientific research documents, whether they are published or not. The documents may come from teaching and research institutions in France or abroad, or from public or private research centers.
L'archive ouverte pluridisciplinaire HAL, est destinée au dépôt et à la diffusion de documents scientifiques de niveau recherche, publiés ou non, émanant des établissements d'enseignement et de recherche français ou étrangers, des laboratoires publics ou privés. 


\title{
A New Parameter Characterising the Ballistic Performance of Ceramics
}

\author{
K. Hoog, H.-J. Ernst and T. Wolf \\ French-German Research Institute of Saint-Louis (ISL), P.O. Box 34, 68301 Saint-Louis cedex, France
}

\begin{abstract}
Impacted by a long rod penetrator at $1800 \mathrm{~m} / \mathrm{s}$ different ceramics of varying thickness and target configurations are investigated. A turning point of the residual penetration curve in the vicinity of thin ceramic layers was not found. The space equivalence factor for vanishing ceramic thickness is introduced as a target configuration independent parameter to describe the ballistic performance of materials. This factor denotes the maximum protection performance of a brittle material by assuming a ductile penetration behaviour. On the basis of this zero thickness value a ballistic performance ranking is presented for $\mathrm{Al}_{2} \mathrm{O}_{3}, \mathrm{~B}_{4} \mathrm{C}, \mathrm{Si}_{3} \mathrm{~N}_{4}, \mathrm{TiB}_{2}$, and glass as well as titanium and a high hardness steel.
\end{abstract}

Résumé : Des céramiques différentes ayant des épaisseurs et des contigurations variées ont impactées par des barreaux longs à une vitesse de $1800 \mathrm{~m} / \mathrm{s}$. Un point d'inflexion de la courbe de la pénétration résiduelle proche des couches minces de céramique n'a pas été trouvé. Le facteur d'équivalence spariale pour des épaisseurs nulles de céramique est introduit comme paramètre indépendant de la configuration de lis cible et décrit la pertormance balistique d'un matériau. Ce facteur indique la performance maximale de protection d'un matériau fragile. en supposant un comportement ductile de pénétration. Basé sur cette valeur limite d'épaisseur nulle, l'ordre hiérarchique de la pertormance balistique est présenté pour les matériaux $\mathrm{Al}_{2} \mathrm{O}_{3}$. $\mathrm{B}_{4} \mathrm{C} . \mathrm{Si}_{3} \mathrm{~N}_{4}, \mathrm{TiB}_{2}$ ainsi que pour le verre, le titane et un acier ultra-dur.

\section{INTRODUCTION}

Depth of penetration (DOP) experiments with long rods impacting ceramic blocks with high velocities yield residual penetrations in a steel backing behind the ceramic tiles. From these residual penetrations different characteristic parameters describing the ballistic performance are derived. It was found that the ballistic performance of ceramics depends on both the thickness of the ceramic block and its constructive environment, often called confinement. The ballistic performance of thick ceramic targets decreases with increasing ceramic thickness. Though the environmental influence on the ballistic performance screening is relatively small, it has been shown that the more the ceramic materials are confined, the more they tend to behave like ductile ones achieving higher ballistic performances $[1,2,3,4,5]$.

Extrapolating the results of thick targets to vanishing ceramic thickness the screening seems to change and the ballistic performance remains configuration dependent without a physical explanation. Therefore, the objective of this investigation is to remove the above-mentioned inconsistency by further DOP experiments with thin ceramic layers and by an improved approximation algorithm.

\section{EXPERIMENTAL RESULTS}

The experiments with thin ceramic tiles (thickness: $4 \mathrm{~mm}$ to $16 \mathrm{~mm}$, lateral dimensions: $100 \times 100 \mathrm{~mm}^{2}$; materials: $\mathrm{Al}_{2} \mathrm{O}_{3}, \mathrm{~B}_{4} \mathrm{C}$, and $\mathrm{TiB}_{2}$ as well as glass) are designed in nearly the same way as for the thick targets [5]. The thin ceramic component is only investigated in two extreme environments: "unconfined" and "totally confined", leaving apart laterally confined configurations. In the unconfined case the ceramic tile is merely placed in front of a steel backing of semi-infinite thickness and in the totally confined case it is completely encased by steel plates. The frontal plate containing a hole in the impact region is removed for the laterally confined configuration. The impacting penetrator consists of a heavy alloy rod (tungsten, diameter: $7.25 \mathrm{~mm}$, length: $145 \mathrm{~mm}$, mass: $105 \mathrm{~g}$ ) attacking at a constant velocity of approx. 
$1800 \mathrm{~m} / \mathrm{s}$. For each ceramic block thickness $\mathrm{t}_{\mathrm{z}}$ an appropriate residual depth of penetration in the steel backing $P_{r e s}$ is measured and compared to the depth of penetration $P_{\text {ref }}$ attained in a semi-infinite reference steel block under equal impact conditions. Backing and reference target consist of RHA.

To compensate for the scattering of the impact velocities a normalized formulation for target thickness and residual penetration is used:

$$
t_{z, n}=t_{z} / P_{r e f} \text { and } P_{r e s, n}=P_{r e s} / P_{r e f} .
$$

Ballistic performance is directly given by the latter expression, but it is more convenient to use another quantity called equivalence factor describing the space gain (subscript $\mathrm{s}$ ) or the mass gain (subscript $\mathrm{m}$ ) related to the ceramic block thickness. The space equivalence is given by

$$
F_{s}=\left(1-P_{r e s, n}\right) / t_{z, n} ;
$$

multiplying it by the density ratio $\rho_{\text {ref }} / \rho$ the mass equivalence follows.

Typical results for the $\mathrm{P}_{\mathrm{res}, \mathrm{n}}$ - and $\mathrm{F}_{\mathrm{s}}$-dependence on $t_{\mathrm{z}, \mathrm{n}}$ and on the configurations are exemplarily shown for $\mathrm{TiB}_{2}$ in figure 1 . The diagrams also include former results with thick targets [6]. In the literature indications are found that a higher order regression of the DOP data yields a turning point in the
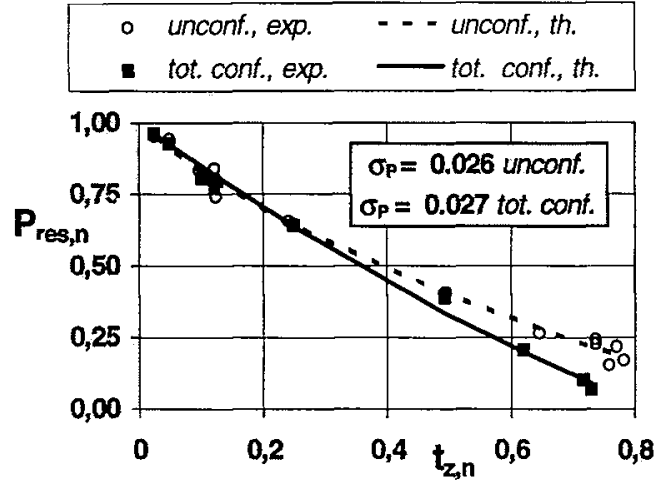
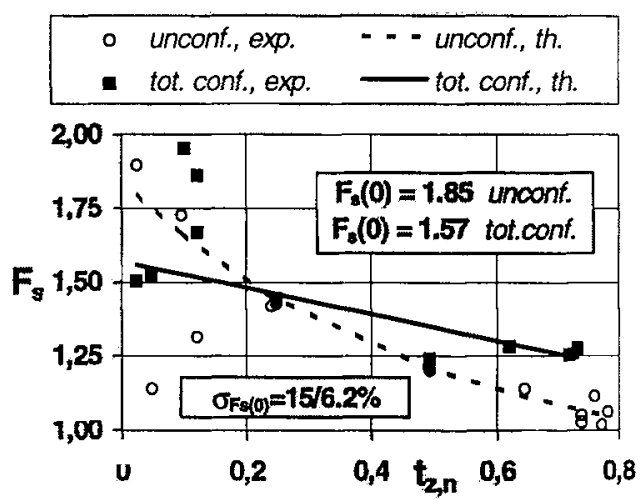

Figure 1: $\mathrm{P}_{\text {res,n }}$ and $\mathrm{F}_{\mathrm{s}}$ dependence on $\mathrm{t}_{\mathbf{z}, \mathrm{n}}$ for $\mathrm{TiB}_{2}$

$\mathrm{P}_{\mathrm{res}, \mathrm{n}}$-curve in the region of small ceramic thickness [7]. In the left-hand diagram of figure 1 an attempt

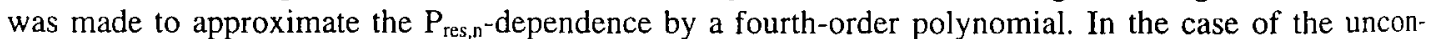
fined configuration the higher order coefficients are evaluated with a high uncertainty and no point of inflection was found in the whole thickness region. In the case of a total confinement only a second order fit was appropriate. When observing the right-hand diagram with the $\mathrm{F}_{\mathrm{s}}$-dependence for the unconfined ceramic the experimental points may suggest a slight decrease for the vanishing thickness indicating the

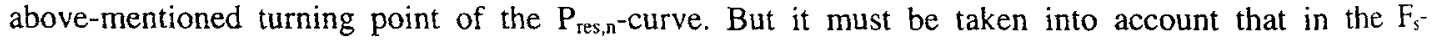
representation the experimental points for the lower thickness should be shown with very large error bars whereas the $\mathrm{P}_{\mathrm{res}, \mathrm{n}}$-representation has a thickness independent error distribution. Furthermore, it can be seen that the configuration influence changes completely in this $\mathrm{F}_{\mathrm{s}}$-fit: the totally confined configuration reaches a lower limit value of $F_{s}$ for $t_{z}=0$ than the unconfined one, though the experimental values for thin layers do not differ in this manner.

Consequently, the $\mathrm{TiB}_{2}$ experiments with thin layers do not remove the above-mentioned inconsistency. The DOP experiments with $\mathrm{Al}_{2} \mathrm{O}_{3}, \mathrm{~B}_{4} \mathrm{C}$, and glass yield similar results. In their $\mathrm{F}_{\mathrm{s}}$-representations it can be seen too that the configuration caused difference diminishes for small ceramic thickness. These experimental results lead to the physically obvious assumption that the equivalence factor of a ceramic material should have the same limit at zero thickness for all target configurations. 


\section{EVALUATION}

\subsection{New Theoretical Approach}

This assumption is equivalent to the hypothesis that the very beginning of the penetration process is not influenced by confinement means far away from the impact zone. As waves (e.g. shock waves) have finite propagation velocities there exists a limit of penetration depth or ceramic thickness for any given configuration below which reflected waves cannot cause any predisturbance of the ceramics in front of the impactor.

Therefore, a corresponding constraint has been introduced into the approximation algorithm by applying an appropriate exponential fit now instead of the polynomial one which was only introduced to check an assumed turning point:

$$
F_{s}=F_{s}(0) \cdot \exp \left(-\gamma \cdot t_{z, n}\right)
$$

This formulation for the space equivalence factor yields an according formula for the normilized residual penetration

$$
P_{\text {res }, n}=I-F_{s}(0) \cdot t_{z, n} \cdot \exp \left(-\gamma \cdot t_{z, n}\right)
$$

Some relations are of special interest:

$$
\begin{gathered}
F_{s}=-\frac{d P_{r e s, n}}{d t_{z, n}} \cdot\left(1+\gamma \cdot t_{z, n}\right)^{-I} \text { and } \\
F_{s}(0)=\exp \left(\gamma \cdot T_{z, n}\right) / T_{z, n} \text { with } P_{r e s, n}\left(T_{z, n}\right)=0 .
\end{gathered}
$$

By applying the $\mathrm{F}_{\mathrm{s}}$-fitting-function to the efficiency factors [5] which respectively describe the space gain and the mass gain of the whole target as compared to the reference target, we get the space efficiency factor

$$
E_{s}=\left[I+t_{z, n}\left(I-F_{s}(0) \cdot \exp \left(-\gamma \cdot t_{z, n}\right)\right)\right]^{-1},
$$

and with the above-mentioned density relation the mass efficiency factor

$$
E_{m}=\left[1+t_{z, n} \cdot\left(\rho / \rho_{r e f}-F_{s}(0) \cdot \exp \left(-\gamma \cdot t_{z, n}\right)\right)\right]^{-1} .
$$

The values of the approximation coefficient $\gamma$ as well as the normalized ballistic limit thickness $\mathbf{T}_{\mathbf{z}, \mathbf{n}}$ depend on both the ceramic material and the target configuration, but the above-mentioned hypothesis implies that $F_{s}(0)$ has the same value for all configurations. This means that the zero thickness limit of the space equivalence factor $F_{s}(0)$ characterises the material behaviour under the considered ballistic loading. Such a value for a distinct $t_{z, n}$ which only depends on the material does not exist for the efficiency factor.

\subsection{Results}

The application of this approximation algorithm to all DOP experiments of one material, i.e. including all configurations and the total thickness range, is called global exponential $F_{s}$-fit later on. If $n$ is equal to the number of different configurations investigated for the considered material, this algorithm yields $n+1$ fitting parameters. Results are presented for the materials $\mathrm{Al}_{2} \mathrm{O}_{3}, \mathrm{~B}_{4} \mathrm{C}, \mathrm{TiB}_{2}$, and glass.

In Figure 2 two diagrams are given showing $\mathrm{F}_{s}\left(\mathrm{t}_{\mathrm{z}, \mathrm{n}}\right)$-curves as well as the experimental data for $\mathrm{TiB}_{2}$ on the left-hand side and for $\mathrm{B}_{4} \mathrm{C}$ on the right-hand side. The curves and the experimental points are distinguished according to the different confinement configurations, i.e. unconfined, laterally, and totally confined, as indicated in the legend. The $F_{s}(0)$-values which characterise the material are indicated together with the uncertainty of their evaluation. The slope of the $F_{s}$-curve defines the penetration behav- 
iour of the ceramic material in the considered target configuration: the more the $\mathrm{F}_{\mathrm{s}}$-curve approaches the horizontal line passing through $\mathrm{F}_{s}(0)$ (i.e. $\gamma \rightarrow 0$ ), the more the penetration behaviour of a ductile material is reached [5]. It can be seen that $T i B_{2}$ has a higher $F_{s}(0)$-value, but $B_{4} C$ has a more quasi-ductile behaviour for each of its three configurations, the difference between the laterally and the totally confined configurations being negligible. It might be possible that in the case of $\mathrm{TiB}_{2}$ a better confinement reduces the slope, thereby improving the penetration resistance of the ceramic material in this configuration.

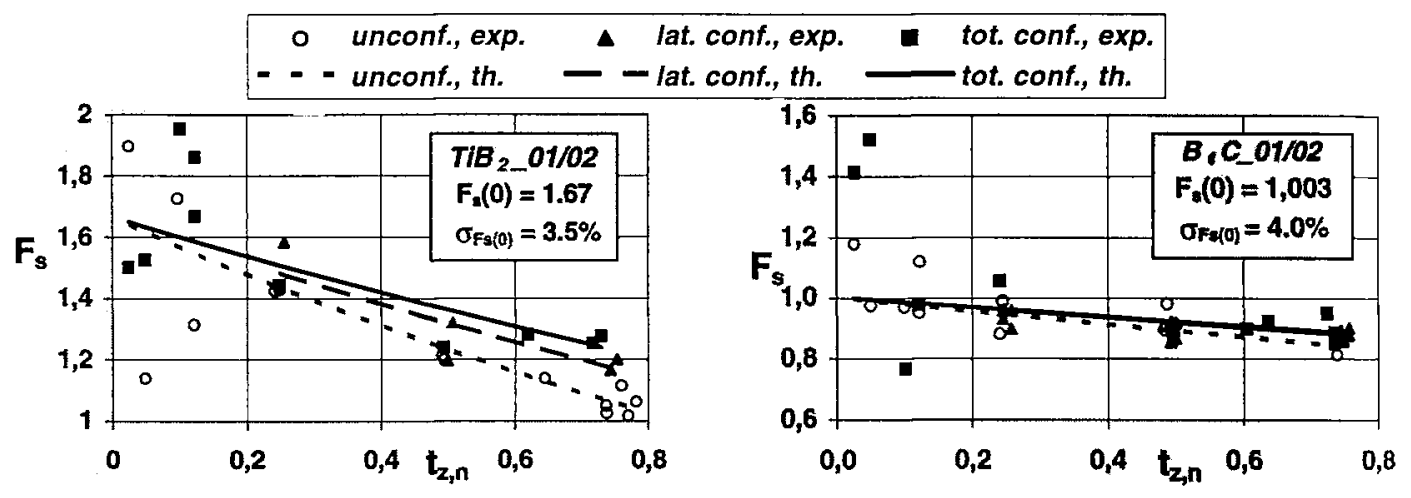

Figure 2: $\mathrm{F}_{\mathrm{s}}$ dependence on $\mathrm{t}_{\mathrm{z}, \mathrm{n}}$ for $\mathrm{TiB}_{2}$ and $\mathrm{B}_{4} \mathrm{C}$

The results for $\mathrm{Al}_{2} \mathrm{O}_{3}$ and glass shown in figure 3 are similar to those obtained for $\mathrm{B}_{4} \mathrm{C}$ regarding the quasi-ductile penetration behaviour in the totally confined configurations. For glass the ductile behaviour seems to be approached already in the unconfined target, but the relatively high scattering of the experi-

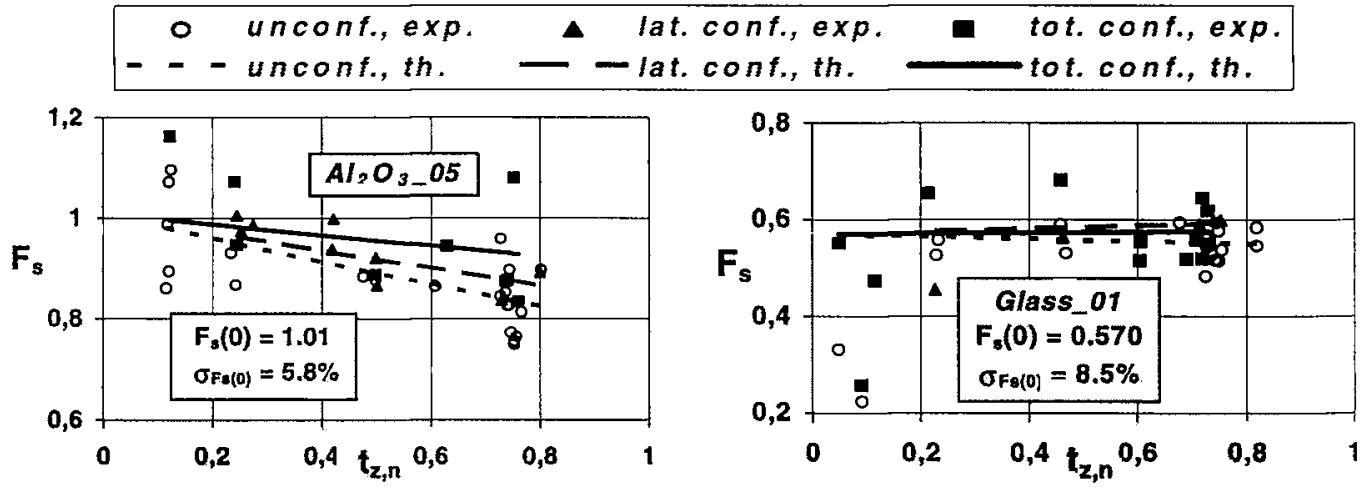

Figure 3: $\mathrm{F}_{\mathrm{s}}$ dependence on $\mathrm{t}_{z, \pi}$ for $\mathrm{Al}_{2} \mathrm{O}_{3}$ and glass

Approximation coefficients $\gamma$ of some ceramics in different configurations

\begin{tabular}{|c|c|c|c|}
\hline Material & unconfined & lat. confined & tot. confined \\
\hline $\mathrm{TiB}_{2}$ & 0.604 & 0.472 & 0.405 \\
$\mathrm{~B}_{4} \mathrm{C}$ & 0.232 & 0.173 & 0.165 \\
$\mathrm{Al}_{2} \mathrm{O}_{3}$ & 0.251 & 0.190 & 0.111 \\
glass & 0.043 & -0.050 & -0.015 \\
\hline
\end{tabular}


tal results may change this statement. This can also be deduced from the unusually high uncertainty of the $\mathrm{F}_{\mathrm{s}}(0)$-value. The small increase of the space equivalence factor with growing glass thickness in the confined cases has to be interpreted in the same manner. The confinement influenced approximation coefficients which define the slope of the $\mathrm{F}_{\mathrm{s}}$-curves are summarised for all brittle materials under consideration in the table above. The relatively large differences of all the $\gamma$-values of $\mathrm{TiB}_{2}$ as compared to the other materials again indicate that an amount of ballistic performance is still available.

\subsection{Thickness and Configuration Independent Ranking}

A screening of the ballistic performance for the investigated brittle materials can be deduced from the values of the initial equivalence factors, i.e. $F_{s}(0)$ and $F_{m}(0)$. This ranking is shown as a bar diagram in figure 4 including two further short bars for the standard deviation of the evaluation for the equivalence factors.

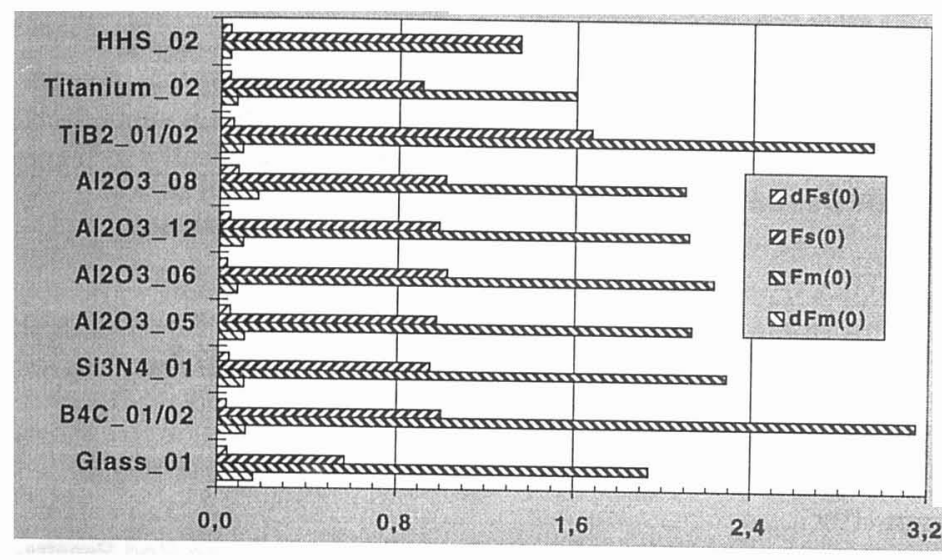

Figure 4: Zero thickness equivalence ranking

As can be seen $\mathrm{Si}_{3} \mathrm{~N}_{4}$ and three more aluminas were added as brittle materials, as well as titanium and a high hardness steel of French origin which are wellknown metallic armour materials for comparison sake. It was not possible to investigate the latter materials with the same number of experiments and thickness and/or confinement variations. This can be seen from the relatively large error bars in the case of $\mathrm{Al}_{2} \mathrm{O}_{3} \_08$, e.g.. Nevertheless, it is possible to roughly evaluate the zero thickness equivalence

factor based on the experimental data for thicker blocks in only one configuration.

Regarded collectively, figure 4 shows that $\mathrm{B}_{4} \mathrm{C}$ has the highest zero thickness mass equivalence which is mostly due to the small density of this material followed by $\mathrm{TiB}_{2}$. $\mathrm{TiB}_{2}$ is the material amongst the considered ones with the highest $F_{s}(0)$-value. In the $F_{s}$-screening there are no significant differences between the aluminas, $\mathrm{B}_{4} \mathrm{C}$ and $\mathrm{Si}_{3} \mathrm{~N}_{4}$; glass is in the last position of all brittle materials. It should be repeated in this context, that low density materials, e.g. glass and $\mathrm{B}_{4} \mathrm{C}$, generally show the highest increases of the $\mathrm{F}_{\mathrm{m}}(0)$-factor as compared to the $\mathrm{F}_{s}(0)$-factor. Next to $\mathrm{TiB}_{2}$ the high hardness steel has the highest zero thickness space equivalence whereas its mass equivalence even ranges behind that of glass, which is the brittle material with the smallest zero space equivalence. Titanium has $F_{s}(0)$ values slightly and $F_{m}(0)$ factors significantly below the aluminas.

From this it can be seen that well-confined ceramics are still useful as armour materials. On the other hand, the fact must be taken into account, that no additional volumes and masses for any confinement enter into these calculations of the zero thickness equivalence factor, which might alter the advantage for the ceramics evaluated in such a way.

Comparing the ballistic performance screening of $\mathrm{Al}_{2} \mathrm{O}_{3} \_05, \mathrm{~B}_{4} \mathrm{C}, \mathrm{TiB}_{2}$, and glass, given in [5] for totally confined ceramic blocks of $120 \mathrm{~mm}$ thickness to the results shown in the diagram of figure 4 for the same materials, no qualitative change is found. Quantitatively, the $F_{m}(0)$-value of $B_{4} C$, e.g., shows a relatively small increase which may indicate that a quasi-ductile penetration behaviour of this material is, to a certain degree, already approached by the total confinement. The $\mathrm{F}_{\mathrm{m}}(0)$-value of $\mathrm{TiB}_{2}$ on the other hand has distinctively increased, which may signify again that the potential of ballistic performance of this material has not yet been completely activated by this confinement configuration. 


\section{CONCLUSIONS}

A ceramic thickness less than half a projectile calibre has not been considered, because it is hardly possi. ble to get sufficient results prevailing over the scattering of ballistic tests. From the evaluation of a lot of DOP-experiments with small and big ceramic block thickness under different confinement configurations the existence of a turning point of the $\mathrm{P}_{\mathrm{res}, \mathrm{n}}\left(\mathrm{t}_{\mathrm{z}, \mathrm{n}}\right)$-curve seems to be improbable. The chosen exponential evaluation adequately describes the physical phenomena with a minimal number of fitting parameters. It is very convenient to use only one ballistic parameter together with the material density to scan the applicability of materials for armour design. In fact, the zero thickness equivalence factor deduced from DOP experiments with different confinement configurations is such a factor, because it sufficiently character ises the ballistic performance of brittle and other materials to allow a comparative ranking independent of constructive influences.

Assuming that a horizontal slope of the $\mathrm{F}_{\mathrm{s}}$-curve indicates the maximum ballistic performance, it should be possible to approach this quasi-ductile penetration behaviour of a brittle material by using adequate constructive target configurations.

In the case of glass a slight $\mathrm{F}_{\mathrm{s}}$-increase for growing thickness may be recognised which, of course, needs further experimental verification. If this result could be confirmed something like a supra-ductile penetration behaviour might be thought to exist. Such a material would have a dynamically increasing penetration resistance, e.g. caused by phase transitions.

\section{References}

[1] Hauver G.E., Netherwood P.H., Benck A.F., Gooch W.A., Perciballi W.J., Burkins, M.S., „Variation of Target Resistance During Long-Rod Penetration into Ceramics“, 13th Int. Symp. on Ballistics, Stockholm, Sweden, 1992, Vol. 3, pp. 257-264

[2] Andersen Jr. C.E., Walker J.D., Lankford J., ,Investigations of the Ballistic Response of Brittle Materials", SWRI-Technical Report, 1995

[3] Yaziv D., Partom Y., „The Ballistic Efficiency of Thick Alumina Targets against Long Rod Penetrators“, 14th Int. Symp. on Ballistics, Quebec, Canada, 1993 Vol. 2, pp. 331-340

[4] Westerling L., Lundberg T., „The Influence of Confinement on the Protective Capability of Ceramic Armour at Two Different Velocities", 15th Int. Symp. on Ballistics, Jerusalem, Israel, 1995, Vol. 1, pp. 283-290

[5] Ernst H.-J., Hoog K., Wiesner V., „Ballistic Impact Behaviour of Some Ceramics in Different Environments“, EURODYMAT 94, Oxford, UK, J. Phys. IV, Coll. C8, Suppl. J. Phys. III, Vol. 4 (1994), pp. 677-682

[6] Ernst H.-J., Hoog K., Wiesner V., Wolf T., „DOP and Continuous Cratering Measurements in Differently Confined Ceramics", Europ. Arm. Fighting Vehicle, RMCS, Shrivenham, UK, 1996

[7] Rupert N.L., Grace F.E., „Penetration of Long Rods into Semi-infinite, Bi-element Targets“, 14th Int. Symp. on Ballistics, Quebec, Canada, 1993, Vol. 2, pp. 469-478 